\title{
Special Issue on Stakeholder Thinking: A Tribute to Juha Näsi
}

\author{
R. Edward Freeman · Salme Näsi · Grant Savage
}

Published online: 28 June 2011

(C) Springer Science+Business Media B.V. 2011

On June 25th of 2008, Professor Juha Nasi convened a small mini-conference around the issue of stakeholder thinking and the current state of the art. The conference took place at a beautiful setting in Tampere, Finland as a precursor to a larger meeting of the International Association of Business and Society. Nasi's idea was to have a series of "ten minute papers." Each paper was to be one and only one idea, a crisply articulated view of the author's best thinking or most important comment about the state of the art of stakeholder thinking.

The plan was to do a volume of these ten minute/ten page papers that would capture a moment in the history of stakeholder thinking where it was becoming more accepted around the world. Professor Nasi had long been one of the world leaders in the articulation of stakeholder thinking, and had actively been teaching stakeholder thinking since the 1970s.

Sadly, on September 7th of that year, Juha passed away after a long bout with cancer. We lost a dear friend and loved one. Stakeholder theory lost one of its originators and one its most original developers. We offer this volume of "ten minute" papers in tribute to the life of Professor Juha Nasi and, as he would want it, towards the development of the ideas that have come to be known as stakeholder theory.

\footnotetext{
R. E. Freeman $(\bowtie)$

University of Virginia, Charlottesville, VA, USA

e-mail: freemane@darden.virginia.edu

S. Näsi

University of Tampere, Tampere, Finland

G. Savage

Uinversity of Alabama, Birmingham, AL
} 